\title{
A panel study on real interest rate parity in East Asian countries: pre- and post- liberalization era
}

\begin{abstract}
This study examines the mean reverting behavior of real interest differentials in ten Asian economies using Japan as the base country. We obtain a number of interesting results: first, the conventional ADF test fails to support Real Interest Parity (RIP) for at least half of the countries, even for the post-financial liberalization period. Second, the evidence based on panel unit root tests demonstrates that real interest rate differentials exhibit mean reverting behavior and are characterized by long-memory dynamics. Finally, the evidence suggests that deviations from RIP have a half-life of approximately 6 to 7 months.
\end{abstract}

Keyword: Real interest differentials; Mean-reversion; Half-life; Panel unit root tests 